\title{
Actuarial Analysis of Single Life Status and Multiple Life Statuses
}

\author{
Abonongo John ${ }^{1,}$, , Luguterah Albert ${ }^{2}$ \\ ${ }^{1}$ Department of Mathematics, Kwame Nkrumah University of Science and Technology, Kumasi, Ghana \\ ${ }^{2}$ Department of Statistics, University for Development Studies, Navrongo, Ghana
}

Email address:

abonongojohn@gmail.com (A. John)

${ }^{*}$ Corresponding author

\section{To cite this article:}

Abonongo John, Luguterah Albert. Actuarial Analysis of Single Life Status and Multiple Life Statuses. American Journal of Theoretical and Applied Statistics. Vol. 5, No. 3, 2016, pp. 123-131. doi: 10.11648/j.ajtas.20160503.17

Received: April 12, 2016; Accepted: April 22, 2016; Published: May 10, 2016

\begin{abstract}
Actuaries frequently employ probability models to analyse situations involving uncertainty. They are also not simply interested in modelling the future states of a subject but also model cash flows associated with future states. This study compared single life status and multiple life statuses using life functions. The expected time until death, annuity payments, insurance payable and premiums were estimated using age as a risk factor. The analysis also employed the De Moirve's law on mortality in estimating the rate of mortality. The analysis revealed that, the expected time until death for single life status and multiple life statuses are all increasing functions of age. It was realized also that, the premium for single life status was increasing with age and the same with multiple life statuses. But the premium for single life was higher than multiple life statuses. In the case of the multiple life statuses, it was revealed that, premium for joint life was higher than the last survivor and that a change in the interest rate or force of interest and the benefit did not changed the trend in premium payments.
\end{abstract}

Keywords: Single Life Status, Multiple Life Statuses, Annuity, Insurance and Premium

\section{Introduction}

Actuarial practice indorses that its scientific base is extensively applicable in life insurance. Therefore actuaries have established a large range of models and varieties of methods and techniques in order to carry out professed actuarial calculations. One of the most important reasons for actuarial modelling is to introduce reliable methods for the practical pricing of insurance contracts, i.e. for the calculation of premium, which the insured life should pay to the insurer, so that the latter will pay his or her next-of-kin the insured amount on the occurrence of the insured event. Another actuarial calculation is the valuation of an insurance contract, thus the determination of its value during the lifetime of the contract; insurance reserve, for which special requirements apply with regard to how the insurer can invest the assets backing it and which forms the base for assessing the creditworthiness of the insurer; its ability to meet its liabilities now and in the future. A traditional assumption in the theory of multiple life contingencies is that the remaining life times of the lives involved are mutually independent. Computational feasibility rather than practicality seems to be the main reason for making this assumption. Such effects may have a significant influence on present values related to multiple life actuarial functions.

[8] and [3] showed alternative ways of modelling dependence of times of death of coupled lives. They released a significant degree of positive correlation between lifetimes. This implies that, joint life annuities were under-priced while last survivor annuities are over-priced. [2] presented boundaries of single premiums for last survivor annuities. [7] and [6] studied bounds of single premiums. These studies showed the impact of dependency of two remaining lifetimes on the pricing of life insurance products on the lives concerned. Dependency, however, also affected the valuation of such contracts over time. The reserves were based on laws of mortality which apply to the policy valuation date. If the remaining lifetimes of a couple are dependent at the outset of a policy, then any of the two lives' survival probabilities may depend on the life status of the partner. Moreover, the joint 
distribution of remaining lifetimes, given the survival of both partners to a certain date, is affected as well. [16] showed that a lot of well-known relationships between probabilities and single premiums in multiple life contingencies are not valid in case of dependent lifetimes. They established that, the validity of those relationships can be restored if the definition of individual survival probabilities allows for the life status of the partner.

Standard actuarial theory of multiple life insurance assume the independence of the future lifetimes of the insured lives. This may occur when a policy is issued to a married couple. Numerous clinical studies have showed that broken heart syndrome may cause an increase in the mortality rate after the death of a spouse [14] and [11]. Also in insurance and annuities, multiple life model play an important role and the application of multiple life actuarial models are common. The investment income from a fund can be paid to a group of beneficiaries as long as at least one of the group survives [1].

[10] extended the classical analysis of the endowment contract on a single life to multiple lives, covering the jointlife and the last survivorship status. The results indicated that, the independence assumption overestimated the jointlife net single and level premiums and underestimates the last survivor net single and level premiums. [15] investigated the condition under which multiple life models can be replaced by single life models, they proved that in a survivorship group, the force of mortality of the group must follow Gompertz law provided that, for the joint-life status of very two lives, one can find a single-life status whose time untildeath's distribution is equal the joint-life status. Hence, the assumption that, the force of mortality follows Gompertz's law is the necessary and sufficient criterion to guarantee that every joint-life status survival pattern can be replaced by a single-life status in the group.

[4] used the Frechet-Hoeffding bounds and Norberg's Markov model in determining the effect of dependence of future lifetimes of couples with much emphases on the actuarial present values of widow's pension benefit. Their results showed an economically significant positive dependence between joint lives: in Norbergs model, the amount of premium were reduced approximately $10 \%$ compared to the standard model that assumes independence. Also, [5] showed that the effect of a possible dependence was rather moderate for classical multiple life contracts at about $5 \%$.

Moreover, other models can be used to incorporate dependencies between life times, for example, the frailty models described by [13] or Markov models as described by [12]. [9] re-investigated joint mortality functions and the assertion that relates the joint life and last survivor random variables. They realized that the common assertion that the sum of the lifetime of joint life and last survivor were equal to the sum of the lifetimes of the single statuses was true and modified the definition of the statuses so that this common assertion holds. They used copula model to indicate that the life insurance premiums with spousal status classification are lower than those without the classification and that the percentage differences are higher for older spouses and for higher interest rates.

The purpose of this paper is investigate the pricing of insurance for single-life status and multiple-life statuses using age as a risk factor. This is to provide insurers with the concept of insurance pricing using age as a risk factor and to give the insured information on the nature premium or annuity payments to be made pertaining to age.

\section{Materials and Methods of Analysis}

\subsection{Data Source}

This study employed ages of Ghanaians with reference from the mortality table of the Indian Institute of Actuaries.

\subsection{Methods of Data Analysis}

The mortality table is a tool which in a practical way represents a model of mortality and belongs to the basic mathematical toolbox in life insurance. Most often used in life insurance are complete mortality tables, which contain separate figures for each integer age $x \in\{0,1,2, \ldots, \omega\}$, where $\omega$ is the assumed maximum age, which someone may attain.

\subsubsection{Single Life Theory}

De Moivre's law states that for all ages $x$ such that $0 \leq$ $x<\omega$, the expected number of survivors at age $x$ and constant force of mortality are given by equation (1) and (2);

$$
l_{x}=\omega-x
$$

where, $l_{x}$ is the expected number of survivors at age $x, \omega$ is the terminal age and $x$ is the attained age.

$$
\mu(x)=\frac{1}{\omega-x}
$$

The survival function is given by;

$$
S_{x}(t)=\frac{\omega-(x+t)}{\omega-x}
$$

where $\omega$ is the terminal age.

The expected time until first death is given by;

$$
e_{x}^{o}=\int_{0}^{\omega-x} S_{T(x)}(t) d t
$$

where $S_{T(x)}(t)$ is the survival at time t.

The Actuarial Present Value (APV) is given by;

$$
A_{x}=\frac{a_{\overline{\omega-x} \mid i}}{\omega-x}
$$

where $a_{\overline{\omega-x} \mid}=\frac{1-(1+i)^{-n}}{i}$ is the annuity payment and $i$ is the interest rate.

The annuity-insurance relation is given by;

$$
\ddot{a}_{x}=\frac{1-A_{x}}{d}
$$

where $d=\frac{i}{1+i}$ is the discounting factor and $A_{x}$ is the APV.

The premium is given by; 


$$
P=\frac{b A_{x}}{\ddot{a}_{x}}
$$

where $b$ is the benefit, $A_{x}$ is the APV and $\ddot{a}_{x}$ is the annuity.

For a continuous whole life insurance, the APV using a constant force model is given by;

$$
\bar{A}_{x}=\frac{\mu}{\mu+\delta}
$$

where $\mu$ is the constant force of mortality and $\delta$ is the force of interest. The annuity for a continuous whole life insurance is given by;

$$
\bar{a}_{x}=\frac{1}{\mu+\delta}
$$

where $\mu$ is the constant force of mortality and $\delta$ is the force of interest.

\subsubsection{Multiple Life Theory}

In multiple life theory consisting of two lives, the joint probability distribution of $(T(x), T(y))$ can be in two distinct forms; namely

a Joint Life Status

The status is said to fail at the first time of failure of one of the component lives or fails upon the death of one of the component lives. The waiting time $\mathrm{T}_{1}$ until failure of the status is given by;

$$
\mathrm{T}_{1}=\min \{\mathrm{T}(\mathrm{x}), \mathrm{T}(\mathrm{y})\} \text { or } \mathrm{T}(\mathrm{x}, \mathrm{y})=\min \{\mathrm{T}(\mathrm{x}), \mathrm{T}(\mathrm{y})\}
$$

The status survives $t$ years from now if $\mathrm{T}_{1}>\mathrm{t}$.

b Last Survivor Status

The status is said to fail at the last time of failure of the component lives or fails upon the death of the last component lives. The waiting time $\mathrm{T}_{2}$ until failure of the status is given by;

$$
\mathrm{T}_{2}=\max \{\mathrm{T}(\mathrm{x}), \mathrm{T}(\mathrm{y})\} \text { or } \mathrm{T}(\overline{\mathrm{x}}, \mathrm{y})=\max \{\mathrm{T}(\mathrm{x}), \mathrm{T}(\mathrm{y})\}
$$

This status fails within the next $\mathrm{t}$ years if $\mathrm{T}_{2} \leq \mathrm{t}$ (both lives have died in $t$ years). The status is surviving in $t$ years if $\mathrm{T}_{2}>\mathrm{t}$ (second death has not occurred by time $\mathrm{t}$ ).

The Joint Life Status Force of Mortality Function with Independent Lives is given by;

$$
\mu_{x y}(t)=\mu(x+t)+\mu(y+t)
$$

where $\mu(x+t)$ is the force of mortality of a person aged $x+t$ and $\mu(y+t)$ is the force of mortality of a person aged $y+t$.

\subsubsection{Expected Time Until Death for Multiple Life Statuses}

The expected time until first death of the component lives is given by;

$$
e^{o}{ }_{x y}=\frac{1}{\mu_{1}+\mu_{2}}
$$

where $\mu_{1}$ is the constant force of mortality for $(x)$ and $\mu_{2}$ is the constant force of mortality for $(y)$

The expected time until death of the last survivor is given by;

$$
e^{o} \overline{x y}=e^{o}{ }_{x}+e^{o}{ }_{y}-e^{o}{ }_{x y}
$$

where $e^{o}{ }_{x}$ and $e^{o}{ }_{y}$ are the expected time until death for $(x)$ and $(y)$ respectively and $e^{o}{ }_{x y}$ is the expected time until first death of the component lives.

\subsubsection{Insurance for Multiple Life Statuses}

For a continuous whole life insurance for joint lives, the APV using a constant force model is given by;

$$
\bar{A}_{x: y}=\frac{\mu_{1}+\mu_{2}}{\mu_{1}+\mu_{2}+\delta}
$$

where $\mu_{1}$ is the constant force of mortality for $(x)$ and $\mu_{2}$ is the constant force of mortality for $(y)$ and $\delta$ is the force of interest.

For a continuous whole life insurance for the last survivor, the APV using a constant force model is given by;

$$
\bar{A}_{\bar{x}: y}=\bar{A}_{x}+\bar{A}_{y}-\bar{A}_{x: y}
$$

\subsubsection{The Annuities for Multiple Life Statuses}

The Actuarial Present Value (APV) for Joint Life Annuity is given by;

$$
\bar{a}_{x: y}=\frac{1}{\mu_{1}+\mu_{2}+\delta}
$$

where $\mu_{1}$ is the constant force of mortality for $(x)$ and $\mu_{2}$ is the constant force of mortality for $(y)$ and $\delta$ is the force of interest.

The APV of the last survivor annuity is given by;

$$
\bar{a}_{\overline{x: y}}=\bar{a}_{x}+\bar{a}_{y}-\bar{a}_{x: y}
$$

where $\bar{a}_{x}$ and $\bar{a}_{y}$ are the annuities for a continuous whole life insurance of $(x)$ and $(y), \bar{a}_{x: y}$ is APV for Joint Life Annuity.

\subsubsection{Premium for Multiple Life Statuses}

The premium for Joint Life is given by;

$$
P=\frac{b \bar{A}_{x: y}}{\bar{a}_{x: y}}
$$

where $b$ is the benefit, $\bar{A}_{x: y}$ is the APV for the continuous whole life insurance for Joint life and $\bar{a}_{x: y}$ is the APV for Joint Life Annuity.

The premium for Last survivor is given by;

$$
P=\frac{b \bar{A} \overline{x: y}}{\bar{a}_{\bar{x}: y}}
$$

where $b$ is the benefit, $\bar{A} \overline{x: y}$ is the APV for the continuous whole life insurance for the last survivor and $\bar{a}_{\bar{x}: y}$ is the APV of the last survivor annuity.

\section{Results and Discussion}

From figure 1, the mortality rate was seen as an increasing function of age. There was a smaller mortality rate from age 1 to age 49 but with an increasing mortality rate from age 50 upwards indicating that mortality rate is an increasing function of age. From age 80, the mortality rate raises to 1 in 
probability indicating that the chances of death is higher as one approaches the terminal age and as such requires higher premium payments. The expected time until death was seen as a decreasing function of age. At age 1, the expected time until death was almost the same as the terminal age. Also the expected time until death was almost zero at age 80 upwards since it was approaching the terminal age. The insurance payment gradually increases with age, thus from age 1 there was insurance payment which was lesser than payments at age 65 upwards. Also as ones age increases, the premium payments also increases. The annuity payments were seen as
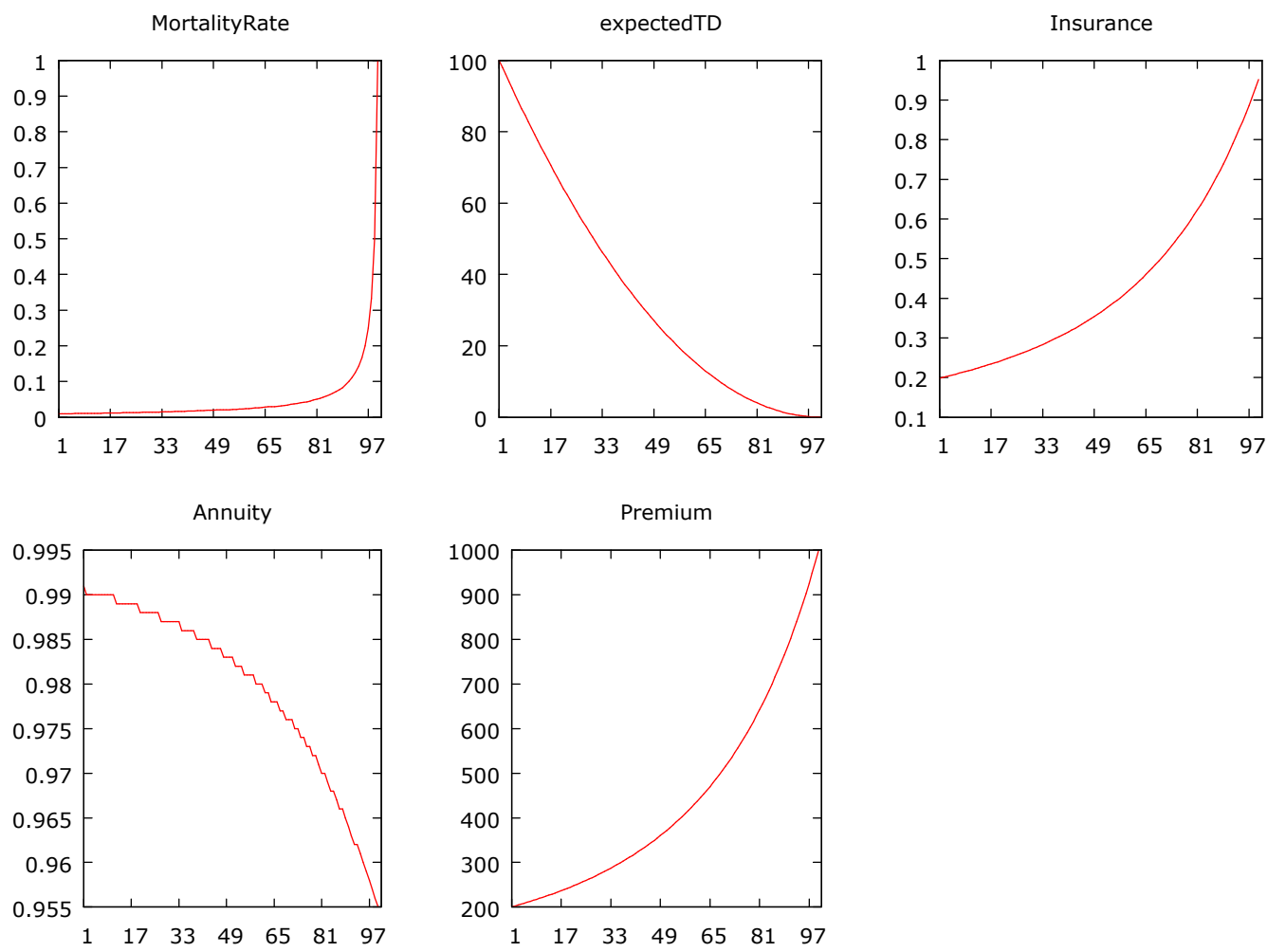

Figure 1. A graph of Mortality, Expected time until death, insurance, annuity and premium for Single Life.

Table 1, shows the estimates for Single Life Status. The constant force of mortality, from age 0 to 4 was constant at 0.010 rate per death, age 5 to 13 have 0.011 rate per death indicating a 0.001 increase from the previous cohort (age 0 to 4). Age 14 to 19 have 0.012 rate per death with age 20 to 25 having 0.013 rate per death. Also, age 26 to 31 have 0.014 rate per death. Age 32 to 35 have 0.015 rate per death with age 36 to 39 having 0.016 rate per death. A mortality rate difference of 0.001 existed for the cohorts (age 40 to 42 , age 43 to 45 , age 46 to 48 , age 49 to 51 , age 52 to 53 , age 54 to 55 , age 56 to 57 and age 58 to 59 ) respectively from the previous cohort (age 36 to 39 ) indicated that the mortality rate for each cohort was the same. From age 60 to 99, the mortality rate kept increasing until it was 1.000 at age 99 . At the terminal age, there is an assumption that no person reaches that age and thus there will not be any mortality at that age. All these indicated that according to De Moivres Law, mortality is an increasing function of age. The expected time until death of each individual age was not the same, thus decreasing from time 100 years for age 0 to time 0 years for a decreasing function of age, meaning once the age goes up, the regular payments reduces. Thus the premium at age 1 to age 10 were quite lesser than premiums thereafter. It could be seen that from age 12 upwards the premium was increasing with age and that approaching the terminal age the premium was almost closer to the benefit. This indicates that, in pricing life insurance age plays a crucial role in determining the premium payments for the insurance coverage in that the higher ones age, the higher the premium and vice versa when other risk factors are held constant. age 100. This indicates that, considering the age of an individual with all other perils held constant, the expected time until death was a decreasing function of age. The Actuarial Present Value (APV) for the individual lives was also not the same and thus shows an increasing function of age (from 0.198 for age 0 to 0.952 for age 99) since the pricing of life insurance takes into consideration the age of the individual. The annuity payments are decreasing function of age thus 0.991 for age 0 to 0.955 for age 99 . For an individual to receive a benefit of $\mathrm{GH} \notin 1000$ with an interest rate of $5 \%$, then premium payment tends to be an increasing function of age, from $\mathrm{GH} \varnothing 200.373$ for age 0 to $\mathrm{GH} \notin 997.625$ for age 99. But these premium estimates will still be increasing with different interest rates and benefits when all other perils aside attain age are held constant. This shows that, no matter the interest and benefits, an insured for a life policy will have a high premium to pay when the age is high and vice versa. Also insurers of life products must consider the age insured to be able to apply the required premium payments. 
Table 1. Estimates for Single Life Actuarial Functions.

\begin{tabular}{|c|c|c|c|c|c|}
\hline \multicolumn{3}{|c|}{ Age } & \multicolumn{3}{|c|}{$\mathbf{i}=\mathbf{5} \%$ and $\mathbf{b}=\mathbf{1 0 0 0}$} \\
\hline $\mathbf{x}$ & $\mu(\mathbf{x})$ & $\mathbf{e}^{\mathbf{0}}{ }_{x}$ & $\mathbf{A}_{\mathbf{x}}$ & $\ddot{\mathbf{a}}_{\mathrm{x}}$ & Premium (P) \\
\hline 0 & 0.010 & 100.000 & 0.198 & 0.991 & 200.373 \\
\hline 1 & 0.010 & 98.010 & 0.200 & 0.990 & 202.338 \\
\hline 2 & 0.010 & 96.040 & 0.202 & 0.990 & 204.340 \\
\hline 3 & 0.010 & 94.090 & 0.204 & 0.990 & 206.379 \\
\hline 4 & 0.010 & 92.160 & 0.206 & 0.990 & 208.457 \\
\hline 5 & 0.011 & 90.250 & 0.208 & 0.990 & 210.574 \\
\hline 6 & 0.011 & 88.360 & 0.211 & 0.990 & 212.731 \\
\hline 7 & 0.011 & 86.490 & 0.213 & 0.990 & 214.930 \\
\hline 8 & 0.011 & 84.640 & 0.215 & 0.990 & 217.172 \\
\hline 9 & 0.011 & 82.810 & 0.217 & 0.990 & 219.457 \\
\hline 10 & 0.011 & 81.000 & 0.219 & 0.990 & 221.787 \\
\hline 11 & 0.011 & 79.210 & 0.222 & 0.989 & 224.164 \\
\hline 12 & 0.011 & 77.440 & 0.224 & 0.989 & 226.588 \\
\hline 13 & 0.011 & 75.690 & 0.227 & 0.989 & 229.060 \\
\hline 14 & 0.012 & 73.960 & 0.229 & 0.989 & 231.583 \\
\hline 15 & 0.012 & 72.250 & 0.232 & 0.989 & 234.156 \\
\hline 16 & 0.012 & 70.560 & 0.234 & 0.989 & 236.783 \\
\hline 17 & 0.012 & 68.890 & 0.237 & 0.989 & 239.464 \\
\hline 18 & 0.012 & 67.240 & 0.239 & 0.989 & 242.200 \\
\hline 19 & 0.012 & 65.610 & 0.242 & 0.988 & 244.994 \\
\hline 20 & 0.013 & 64.000 & 0.245 & 0.988 & 247.847 \\
\hline 21 & 0.013 & 62.410 & 0.248 & 0.988 & 250.760 \\
\hline 22 & 0.013 & 60.840 & 0.251 & 0.988 & 253.736 \\
\hline 23 & 0.013 & 59.290 & 0.254 & 0.988 & 256.775 \\
\hline 24 & 0.013 & 57.760 & 0.257 & 0.988 & 259.881 \\
\hline 25 & 0.013 & 56.250 & 0.260 & 0.988 & 263.054 \\
\hline 26 & 0.014 & 54.760 & 0.263 & 0.987 & 266.297 \\
\hline 27 & 0.014 & 53.290 & 0.266 & 0.987 & 269.612 \\
\hline 28 & 0.014 & 51.840 & 0.269 & 0.987 & 273.001 \\
\hline 29 & 0.014 & 50.410 & 0.273 & 0.987 & 276.465 \\
\hline 30 & 0.014 & 49.000 & 0.276 & 0.987 & 280.008 \\
\hline 31 & 0.014 & 47.610 & 0.280 & 0.987 & 283.632 \\
\hline 32 & 0.015 & 46.240 & 0.283 & 0.987 & 287.339 \\
\hline 33 & 0.015 & 44.890 & 0.287 & 0.986 & 291.131 \\
\hline 34 & 0.015 & 43.560 & 0.291 & 0.986 & 295.011 \\
\hline 35 & 0.015 & 42.250 & 0.295 & 0.986 & 298.983 \\
\hline 36 & 0.016 & 40.960 & 0.299 & 0.986 & 303.047 \\
\hline 37 & 0.016 & 39.690 & 0.303 & 0.986 & 307.208 \\
\hline 38 & 0.016 & 38.440 & 0.307 & 0.985 & 311.469 \\
\hline 39 & 0.016 & 37.210 & 0.311 & 0.985 & 315.832 \\
\hline 40 & 0.017 & 36.000 & 0.315 & 0.985 & 320.300 \\
\hline 41 & 0.017 & 34.810 & 0.320 & 0.985 & 324.877 \\
\hline 42 & 0.017 & 33.640 & 0.324 & 0.985 & 329.567 \\
\hline 43 & 0.018 & 32.490 & 0.329 & 0.984 & 334.373 \\
\hline 44 & 0.018 & 31.360 & 0.334 & 0.984 & 339.297 \\
\hline 45 & 0.018 & 30.250 & 0.339 & 0.984 & 344.346 \\
\hline 46 & 0.019 & 29.160 & 0.344 & 0.984 & 349.521 \\
\hline 47 & 0.019 & 28.090 & 0.349 & 0.983 & 354.828 \\
\hline 48 & 0.019 & 27.040 & 0.354 & 0.983 & 360.270 \\
\hline 49 & 0.020 & 26.010 & 0.360 & 0.983 & 365.852 \\
\hline 50 & 0.020 & 25.000 & 0.365 & 0.983 & 371.579 \\
\hline 51 & 0.020 & 24.010 & 0.371 & 0.982 & 377.455 \\
\hline 52 & 0.021 & 23.040 & 0.377 & 0.982 & 383.485 \\
\hline 53 & 0.021 & 22.090 & 0.383 & 0.982 & 389.674 \\
\hline 54 & 0.022 & 21.160 & 0.389 & 0.981 & 396.027 \\
\hline 55 & 0.022 & 20.250 & 0.395 & 0.981 & 402.551 \\
\hline 56 & 0.023 & 19.360 & 0.401 & 0.981 & 409.250 \\
\hline 57 & 0.023 & 18.490 & 0.408 & 0.981 & 416.130 \\
\hline 58 & 0.024 & 17.640 & 0.415 & 0.980 & 423.198 \\
\hline 59 & 0.024 & 16.810 & 0.422 & 0.980 & 430.460 \\
\hline 60 & 0.025 & 16.000 & 0.429 & 0.980 & 437.923 \\
\hline 61 & 0.026 & 15.210 & 0.436 & 0.979 & 445.593 \\
\hline 62 & 0.026 & 14.440 & 0.444 & 0.979 & 453.477 \\
\hline
\end{tabular}

\begin{tabular}{|c|c|c|c|c|c|}
\hline \multicolumn{3}{|l|}{ Age } & \multicolumn{3}{|c|}{$i=5 \%$ and $b=1000$} \\
\hline $\mathbf{x}$ & $\mu(\mathbf{x})$ & $\mathbf{e}^{\mathbf{0}}{ }_{\mathrm{x}}$ & $\mathbf{A}_{\mathbf{x}}$ & $\ddot{\mathbf{a}}_{\mathrm{x}}$ & Premium (P) \\
\hline 63 & 0.027 & 13.690 & 0.452 & 0.978 & 461.584 \\
\hline 64 & 0.028 & 12.960 & 0.460 & 0.978 & 469.920 \\
\hline 65 & 0.029 & 12.250 & 0.468 & 0.978 & 478.494 \\
\hline 66 & 0.029 & 11.560 & 0.476 & 0.977 & 487.314 \\
\hline 67 & 0.030 & 10.890 & 0.485 & 0.977 & 496.388 \\
\hline 68 & 0.031 & 10.240 & 0.494 & 0.976 & 505.726 \\
\hline 69 & 0.032 & 9.610 & 0.503 & 0.976 & 515.337 \\
\hline 70 & 0.033 & 9.000 & 0.512 & 0.976 & 525.231 \\
\hline 71 & 0.034 & 8.410 & 0.522 & 0.975 & 535.418 \\
\hline 72 & 0.036 & 7.840 & 0.532 & 0.975 & 545.908 \\
\hline 73 & 0.037 & 7.290 & 0.542 & 0.974 & 556.712 \\
\hline 74 & 0.038 & 6.760 & 0.553 & 0.974 & 567.842 \\
\hline 75 & 0.040 & 6.250 & 0.564 & 0.973 & 579.310 \\
\hline 76 & 0.042 & 5.760 & 0.575 & 0.973 & 591.127 \\
\hline 77 & 0.043 & 5.290 & 0.586 & 0.972 & 603.308 \\
\hline 78 & 0.045 & 4.840 & 0.598 & 0.972 & 615.865 \\
\hline 79 & 0.048 & 4.410 & 0.611 & 0.971 & 628.812 \\
\hline 80 & 0.050 & 4.000 & 0.623 & 0.970 & 642.165 \\
\hline 81 & 0.053 & 3.610 & 0.636 & 0.970 & 655.937 \\
\hline 82 & 0.056 & 3.240 & 0.649 & 0.969 & 670.146 \\
\hline 83 & 0.059 & 2.890 & 0.663 & 0.968 & 684.807 \\
\hline 84 & 0.063 & 2.560 & 0.677 & 0.968 & 699.937 \\
\hline 85 & 0.067 & 2.250 & 0.692 & 0.967 & 715.556 \\
\hline 86 & 0.071 & 1.960 & 0.707 & 0.966 & 731.681 \\
\hline 87 & 0.077 & 1.690 & 0.723 & 0.966 & 748.332 \\
\hline 88 & 0.083 & 1.440 & 0.739 & 0.965 & 765.529 \\
\hline 89 & 0.091 & 1.210 & 0.755 & 0.964 & 783.295 \\
\hline 90 & 0.100 & 1.000 & 0.772 & 0.963 & 801.650 \\
\hline 91 & 0.111 & 0.810 & 0.790 & 0.962 & 820.619 \\
\hline 92 & 0.125 & 0.640 & 0.808 & 0.962 & 840.226 \\
\hline 93 & 0.143 & 0.490 & 0.827 & 0.961 & 860.497 \\
\hline 94 & 0.167 & 0.360 & 0.846 & 0.96 & 881.457 \\
\hline 95 & 0.200 & 0.250 & 0.866 & 0.959 & 903.134 \\
\hline 96 & 0.250 & 0.160 & 0.886 & 0.958 & 925.559 \\
\hline 97 & 0.333 & 0.090 & 0.908 & 0.957 & 948.761 \\
\hline 98 & 0.500 & 0.040 & 0.930 & 0.956 & 972.771 \\
\hline 99 & 1.000 & 0.010 & 0.952 & 0.955 & 997.625 \\
\hline 100 & & 0.000 & & & \\
\hline
\end{tabular}

Also from figure 2, the mortality rate was seen as increasing function of age for the joint life status. From age 1 to 49, the mortality rate was constant until age 50 when it kept increasing all through to the terminal age. The expected time until death for both joint life (ExpectedTDJL) and last survivor (ExpectedTDLS) are seen as a decreasing function of age. But the expected time until death for the last survivor status was higher than the joint life status, and that the expected time until death does not hit zero for the last survivor as it does for the joint life. The insurance payable for both the joint life (InsuranceJL) and last survivor (InsuranceLS) were all increasing function of age but the joint life has a higher insurance payment than the last survivor. The annuity payment was seen as a decreasing function of age with the last survivor (AnnuityLS) having a higher annuity payment than the joint life (AnnuityJL). Nevertheless, the premium payment was seen an increasing function of age. The premium for joint life (PremiumJL) was higher than that of the last survivor (PremiumLS). This indicates that, in considering two lives for life policy, the ages of the two matters in that the age of either life can easily influence the premium payment especially in the case of joint life statuses. 
MortalityRate

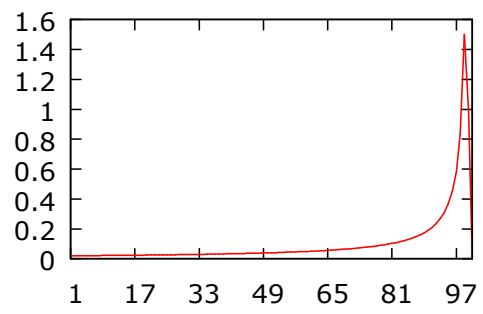

InsuranceJL

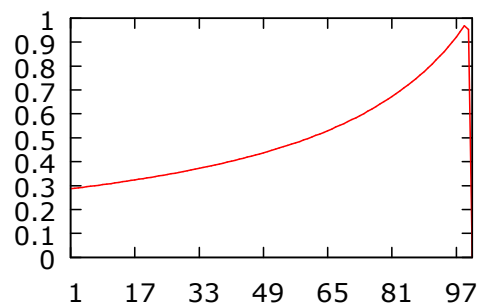

AnnuityLS

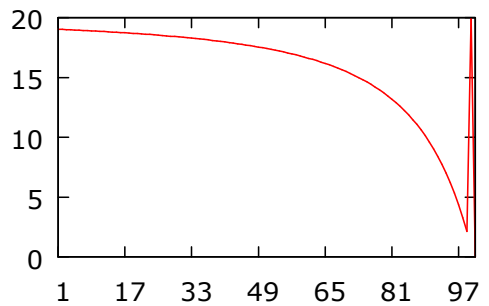

ExpectedTDJL

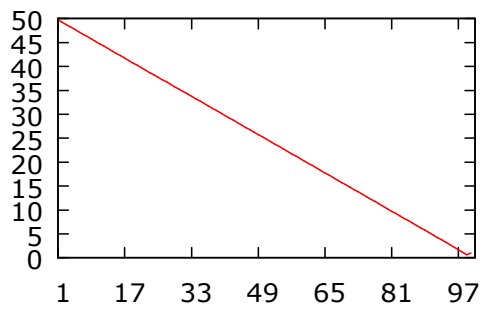

InsuranceLS

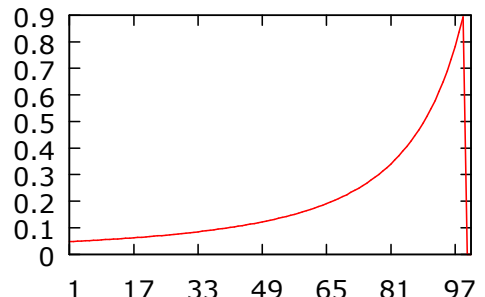

PremiumJL

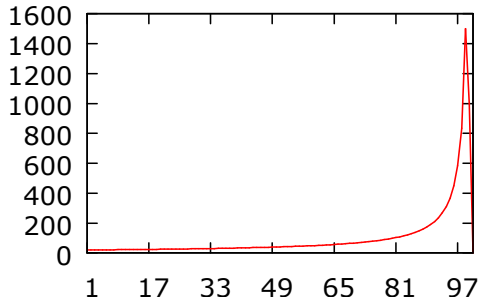

ExpectedTDLS

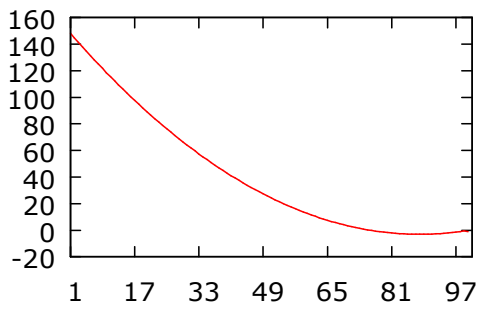

AnnuityJL

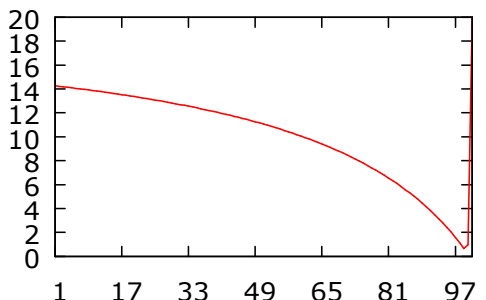

PremiumLS

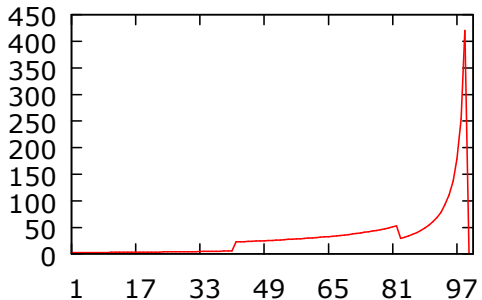

Figure 2. A graph of Mortality Rate, Expected time until death (Joint Life and Last Survivor), Insurance (Joint life and Last survivor), Annuity (Joint life and Last survivor) and Premium (Joint life and Last survivor).

Table 2. Estimates for Multiple Life Actuarial Functions.

\begin{tabular}{|c|c|c|c|c|c|c|c|c|c|}
\hline \multicolumn{5}{|l|}{ Age } & \multicolumn{5}{|c|}{$\delta=5 \%$ and benefit $=1000$} \\
\hline $\mathbf{x}$ & $\mu_{\mathrm{xy}}$ & $\mathbf{e}^{\mathbf{o}}{ }_{\mathrm{xy}}$ & $\mathrm{e}^{\mathbf{0}} \overline{\mathrm{xy}}$ & $\overline{\mathbf{A}}_{\mathrm{xy}}$ & $\overline{\mathbf{A}}_{\overline{\mathbf{x y}}}$ & $\overline{\mathbf{a}}_{\mathbf{x y}}$ & $\overline{\mathbf{a}_{\overline{\mathbf{x y}}}}$ & Premium (P) xy & Premium (P) $\overline{x y}$ \\
\hline 0 & 0.020 & 49.749 & 148.261 & 0.287 & 0.048 & 14.265 & 19.040 & 20.101 & 2.520 \\
\hline 1 & 0.020 & 49.249 & 144.801 & 0.289 & 0.049 & 14.224 & 19.025 & 20.305 & 2.562 \\
\hline 2 & 0.021 & 48.749 & 141.381 & 0.291 & 0.050 & 14.182 & 19.010 & 20.513 & 2.605 \\
\hline 3 & 0.021 & 48.249 & 138.001 & 0.293 & 0.050 & 14.139 & 18.994 & 20.726 & 2.649 \\
\hline 4 & 0.021 & 47.749 & 134.661 & 0.295 & 0.051 & 14.096 & 18.978 & 20.943 & 2.694 \\
\hline 5 & 0.021 & 47.249 & 131.361 & 0.297 & 0.052 & 14.052 & 18.961 & 21.165 & 2.740 \\
\hline 6 & 0.021 & 46.749 & 128.101 & 0.300 & 0.053 & 14.007 & 18.944 & 21.391 & 2.787 \\
\hline 7 & 0.022 & 46.249 & 124.881 & 0.302 & 0.054 & 13.962 & 18.927 & 21.622 & 2.836 \\
\hline 8 & 0.022 & 45.749 & 121.701 & 0.304 & 0.055 & 13.916 & 18.909 & 21.859 & 2.886 \\
\hline 9 & 0.022 & 45.249 & 118.561 & 0.307 & 0.055 & 13.870 & 18.890 & 22.100 & 2.937 \\
\hline 10 & 0.022 & 44.749 & 115.461 & 0.309 & 0.056 & 13.822 & 18.872 & 22.347 & 2.990 \\
\hline 11 & 0.023 & 44.249 & 112.401 & 0.311 & 0.057 & 13.774 & 18.852 & 22.600 & 3.044 \\
\hline 12 & 0.023 & 43.749 & 109.381 & 0.314 & 0.058 & 13.725 & 18.833 & 22.858 & 3.099 \\
\hline 13 & 0.023 & 43.249 & 106.401 & 0.316 & 0.059 & 13.676 & 18.812 & 23.122 & 3.157 \\
\hline 14 & 0.023 & 42.749 & 103.461 & 0.319 & 0.060 & 13.625 & 18.792 & 23.393 & 3.215 \\
\hline 15 & 0.024 & 42.249 & 100.561 & 0.321 & 0.061 & 13.574 & 18.770 & 23.669 & 3.276 \\
\hline 16 & 0.024 & 41.749 & 97.701 & 0.324 & 0.063 & 13.522 & 18.748 & 23.953 & 3.338 \\
\hline 17 & 0.024 & 41.248 & 94.882 & 0.327 & 0.064 & 13.469 & 18.726 & 24.243 & 3.403 \\
\hline 18 & 0.025 & 40.748 & 92.102 & 0.329 & 0.065 & 13.415 & 18.703 & 24.541 & 3.469 \\
\hline 19 & 0.025 & 40.248 & 89.362 & 0.332 & 0.066 & 13.361 & 18.679 & 24.846 & 3.537 \\
\hline 20 & 0.025 & 39.748 & 86.662 & 0.335 & 0.067 & 13.305 & 18.654 & 25.158 & 3.607 \\
\hline 21 & 0.025 & 39.248 & 84.002 & 0.338 & 0.069 & 13.249 & 18.629 & 25.479 & 3.679 \\
\hline 22 & 0.026 & 38.748 & 81.382 & 0.340 & 0.070 & 13.191 & 18.603 & 25.808 & 3.754 \\
\hline 23 & 0.026 & 38.248 & 78.802 & 0.343 & 0.071 & 13.133 & 18.577 & 26.145 & 3.831 \\
\hline 24 & 0.026 & 37.748 & 76.262 & 0.346 & 0.073 & 13.073 & 18.549 & 26.491 & 3.910 \\
\hline 25 & 0.027 & 37.248 & 73.762 & 0.349 & 0.074 & 13.013 & 18.521 & 26.847 & 3.992 \\
\hline 26 & 0.027 & 36.748 & 71.302 & 0.352 & 0.075 & 12.951 & 18.492 & 27.212 & 4.077 \\
\hline 27 & 0.028 & 36.248 & 68.882 & 0.356 & 0.077 & 12.889 & 18.462 & 27.588 & 4.164 \\
\hline 28 & 0.028 & 35.748 & 66.502 & 0.359 & 0.078 & 12.825 & 18.432 & 27.973 & 4.254 \\
\hline
\end{tabular}




\begin{tabular}{|c|c|c|c|c|c|c|c|c|c|}
\hline \multicolumn{5}{|c|}{ Age } & \multicolumn{5}{|c|}{$\delta=5 \%$ and benefit $=1000$} \\
\hline $\mathbf{x}$ & $\mu_{\mathrm{xv}}$ & $\mathbf{e}_{\mathrm{xy}}^{\mathbf{0}}$ & $\mathrm{e}_{\overline{\mathrm{xv}}}^{\mathbf{o}}$ & $\overline{\mathbf{A}}_{\mathrm{xv}}$ & $\overline{\mathbf{A}}_{\overline{\mathbf{x v}}}$ & $\overline{\mathbf{a}}_{\mathrm{xv}}$ & $\overline{\mathbf{a}_{\overline{\mathbf{x v}}}}$ & Premium (P) xy & Premium $(P) \overline{x y}$ \\
\hline 29 & 0.028 & 35.248 & 64.162 & 0.362 & 0.080 & 12.760 & 18.400 & 28.370 & 4.348 \\
\hline 30 & 0.029 & 34.748 & 61.862 & 0.365 & 0.082 & 12.694 & 18.367 & 28.778 & 4.444 \\
\hline 31 & 0.029 & 34.248 & 59.602 & 0.369 & 0.083 & 12.626 & 18.334 & 29.199 & 4.544 \\
\hline 32 & 0.030 & 33.748 & 57.382 & 0.372 & 0.085 & 12.558 & 18.299 & 29.631 & 4.648 \\
\hline 33 & 0.030 & 33.248 & 55.202 & 0.376 & 0.087 & 12.488 & 18.263 & 30.077 & 4.755 \\
\hline 34 & 0.031 & 32.748 & 53.062 & 0.379 & 0.089 & 12.417 & 18.226 & 30.536 & 4.866 \\
\hline 35 & 0.031 & 32.248 & 50.962 & 0.383 & 0.091 & 12.344 & 18.188 & 31.010 & 4.981 \\
\hline 36 & 0.031 & 31.748 & 48.902 & 0.386 & 0.093 & 12.270 & 18.149 & 31.498 & 5.101 \\
\hline 37 & 0.032 & 31.248 & 46.882 & 0.390 & 0.095 & 12.195 & 18.108 & 32.002 & 5.225 \\
\hline 38 & 0.033 & 30.748 & 44.902 & 0.394 & 0.097 & 12.118 & 18.066 & 32.522 & 5.353 \\
\hline 39 & 0.033 & 30.248 & 42.962 & 0.398 & 0.099 & 12.039 & 18.022 & 33.060 & 5.487 \\
\hline 40 & 0.034 & 29.748 & 41.062 & 0.402 & 0.101 & 11.959 & 17.977 & 33.616 & 5.626 \\
\hline 41 & 0.034 & 29.248 & 39.202 & 0.406 & 0.103 & 11.878 & 17.931 & 34.191 & 22.649 \\
\hline 42 & 0.035 & 28.748 & 37.382 & 0.410 & 0.106 & 11.795 & 17.882 & 34.785 & 22.943 \\
\hline 43 & 0.035 & 28.248 & 35.602 & 0.415 & 0.108 & 11.709 & 17.833 & 35.401 & 23.245 \\
\hline 44 & 0.036 & 27.748 & 33.862 & 0.419 & 0.111 & 11.623 & 17.781 & 36.039 & 23.557 \\
\hline 45 & 0.037 & 27.248 & 32.162 & 0.423 & 0.114 & 11.534 & 17.727 & 36.700 & 23.879 \\
\hline 46 & 0.037 & 26.748 & 30.502 & 0.428 & 0.116 & 11.443 & 17.672 & 37.386 & 24.210 \\
\hline 47 & 0.038 & 26.248 & 28.882 & 0.432 & 0.119 & 11.351 & 17.614 & 38.099 & 24.552 \\
\hline 48 & 0.039 & 25.748 & 27.302 & 0.437 & 0.122 & 11.256 & 17.554 & 38.839 & 24.905 \\
\hline 49 & 0.040 & 25.248 & 25.762 & 0.442 & 0.125 & 11.160 & 17.492 & 39.608 & 25.269 \\
\hline 50 & 0.040 & 24.747 & 24.263 & 0.447 & 0.129 & 11.061 & 17.428 & 40.408 & 25.646 \\
\hline 51 & 0.041 & 24.247 & 22.803 & 0.452 & 0.132 & 10.960 & 17.361 & 41.241 & 26.036 \\
\hline 52 & 0.042 & 23.747 & 21.383 & 0.457 & 0.135 & 10.857 & 17.291 & 42.110 & 26.440 \\
\hline 53 & 0.043 & 23.247 & 20.003 & 0.462 & 0.139 & 10.751 & 17.218 & 43.016 & 26.858 \\
\hline 54 & 0.044 & 22.747 & 18.663 & 0.468 & 0.143 & 10.643 & 17.143 & 43.961 & 27.292 \\
\hline 55 & 0.045 & 22.247 & 17.363 & 0.473 & 0.147 & 10.532 & 17.064 & 44.949 & 27.742 \\
\hline 56 & 0.046 & 21.747 & 16.103 & 0.479 & 0.151 & 10.419 & 16.982 & 45.983 & 28.210 \\
\hline 57 & 0.047 & 21.247 & 14.883 & 0.485 & 0.155 & 10.302 & 16.897 & 47.065 & 28.697 \\
\hline 58 & 0.048 & 20.747 & 13.703 & 0.491 & 0.160 & 10.183 & 16.808 & 48.200 & 29.203 \\
\hline 59 & 0.049 & 20.247 & 12.563 & 0.497 & 0.164 & 10.061 & 16.715 & 49.390 & 29.730 \\
\hline 60 & 0.051 & 19.747 & 11.463 & 0.503 & 0.169 & 9.936 & 16.617 & 50.641 & 30.281 \\
\hline 61 & 0.052 & 19.247 & 10.403 & 0.510 & 0.174 & 9.808 & 16.516 & 51.957 & 30.855 \\
\hline 62 & 0.053 & 18.747 & 9.383 & 0.516 & 0.180 & 9.677 & 16.409 & 53.343 & 31.456 \\
\hline 63 & 0.055 & 18.247 & 8.403 & 0.523 & 0.185 & 9.542 & 16.298 & 54.805 & 32.085 \\
\hline 64 & 0.056 & 17.746 & 7.464 & 0.530 & 0.191 & 9.403 & 16.181 & 56.349 & 32.744 \\
\hline 65 & 0.058 & 17.246 & 6.564 & 0.537 & 0.197 & 9.261 & 16.059 & 57.983 & 33.437 \\
\hline 66 & 0.060 & 16.746 & 5.704 & 0.544 & 0.203 & 9.115 & 15.931 & 59.715 & 34.165 \\
\hline 67 & 0.062 & 16.246 & 4.884 & 0.552 & 0.210 & 8.964 & 15.796 & 61.553 & 34.931 \\
\hline 68 & 0.064 & 15.746 & 4.104 & 0.560 & 0.217 & 8.810 & 15.655 & 63.508 & 35.740 \\
\hline 69 & 0.066 & 15.246 & 3.364 & 0.567 & 0.225 & 8.651 & 15.506 & 65.591 & 36.596 \\
\hline 70 & 0.068 & 14.746 & 2.664 & 0.576 & 0.233 & 8.488 & 15.349 & 67.816 & 37.502 \\
\hline 71 & 0.070 & 14.246 & 2.004 & 0.584 & 0.241 & 8.320 & 15.184 & 70.197 & 38.463 \\
\hline 72 & 0.073 & 13.745 & 1.385 & 0.593 & 0.250 & 8.147 & 15.009 & 72.751 & 39.487 \\
\hline 73 & 0.075 & 13.245 & 0.805 & 0.602 & 0.259 & 7.968 & 14.825 & 75.499 & 40.578 \\
\hline 74 & 0.078 & 12.745 & 0.265 & 0.611 & 0.268 & 7.784 & 14.631 & 78.462 & 41.745 \\
\hline 75 & 0.082 & 12.245 & 0.235 & 0.620 & 0.279 & 7.595 & 14.425 & 81.667 & 42.998 \\
\hline 76 & 0.085 & 11.745 & 0.295 & 0.630 & 0.290 & 7.399 & 14.207 & 85.145 & 44.345 \\
\hline 77 & 0.089 & 11.244 & 0.114 & 0.640 & 0.301 & 7.198 & 13.976 & 88.933 & 45.800 \\
\hline 78 & 0.093 & 10.744 & 0.494 & 0.651 & 0.313 & 6.989 & 13.731 & 93.074 & 47.378 \\
\hline 79 & 0.098 & 10.244 & 0.834 & 0.661 & 0.327 & 6.774 & 13.470 & 97.619 & 49.095 \\
\hline 80 & 0.103 & 9.744 & 0.134 & 0.672 & 0.340 & 6.552 & 13.192 & 102.632 & 50.972 \\
\hline 81 & 0.108 & 9.243 & 0.393 & 0.684 & 0.355 & 6.322 & 12.896 & 108.187 & 53.035 \\
\hline 82 & 0.114 & 8.743 & 0.613 & 0.696 & 0.371 & 6.083 & 12.579 & 114.379 & 29.495 \\
\hline 83 & 0.121 & 8.242 & 0.792 & 0.708 & 0.388 & 5.837 & 12.241 & 121.324 & 31.692 \\
\hline 84 & 0.129 & 7.742 & 0.932 & 0.721 & 0.406 & 5.581 & 11.879 & 129.167 & 34.183 \\
\hline 85 & 0.138 & 7.241 & 0.031 & 0.734 & 0.425 & 5.316 & 11.490 & 138.095 & 37.030 \\
\hline 86 & 0.148 & 6.741 & 0.091 & 0.748 & 0.446 & 5.042 & 11.073 & 148.352 & 40.314 \\
\hline 87 & 0.160 & 6.240 & 0.110 & 0.762 & 0.469 & 4.756 & 10.623 & 160.256 & 44.138 \\
\hline 88 & 0.174 & 5.739 & 0.089 & 0.777 & 0.493 & 4.459 & 10.137 & 174.242 & 48.645 \\
\hline 89 & 0.191 & 5.238 & 0.028 & 0.792 & 0.519 & 4.151 & 9.612 & 190.909 & 54.031 \\
\hline 90 & 0.211 & 4.737 & 0.927 & 0.809 & 0.548 & 3.830 & 9.044 & 211.111 & 60.573 \\
\hline 91 & 0.236 & 4.235 & 0.785 & 0.825 & 0.579 & 3.495 & 8.426 & 236.111 & 68.680 \\
\hline 92 & 0.268 & 3.733 & 0.603 & 0.843 & 0.612 & 3.146 & 7.753 & 267.857 & 78.976 \\
\hline 93 & 0.310 & 3.231 & 0.381 & 0.861 & 0.649 & 2.781 & 7.019 & 309.524 & 92.468 \\
\hline 94 & 0.367 & 2.727 & 0.117 & 0.880 & 0.689 & 2.400 & 6.215 & 366.667 & 110.891 \\
\hline 95 & 0.450 & 2.222 & 0.812 & 0.900 & 0.733 & 2.000 & 5.333 & 450.000 & 137.500 \\
\hline 96 & 0.583 & 1.714 & 0.464 & 0.921 & 0.782 & 1.579 & 4.363 & 583.333 & 179.196 \\
\hline 97 & 0.833 & 1.200 & 0.070 & 0.943 & 0.835 & 1.132 & 3.295 & 833.333 & 253.508 \\
\hline 98 & 1.500 & 1.667 & 0.617 & 0.968 & 0.894 & 0.645 & 2.125 & 1500.000 & 420.499 \\
\hline 99 & 1.000 & 1.000 & 0.990 & 0.952 & 0.000 & 0.952 & 20.000 & 1000.000 & 0.000 \\
\hline 100 & 0.000 & & & 0.000 & 0.000 & 20.000 & 0.000 & 0.000 & \\
\hline
\end{tabular}


Table 2, shows the estimates for the joint life and last survivor statuses. For multiple life statuses in this case two lives were considered at a time. The ages were grouped as follows: ages 0 and 1 , ages 1 and 2, ages 2 and 3,.., ages 99 and 100 . The mortality for joint life started from 0.020 for ages 0 and 1 and same for ages 1 and 2 but increases from there to 1.000 for ages 99 and 100. This indicated that, the mortality for joint life was an increasing function of age. The expected time until first death of the component lives (joint life status) was a decreasing function of age, from 50 years for ages 0 and 1, 49 years for ages 1 and 2 to 1 year for ages 99 and 100. This indicated that the expected time until death of the first component lives which can be either of the two depends on the age of any of the two when all other perils are held constant. The expected time until death of the last component lives (last survivor status) was also a decreasing function of age, that was from 148 years for ages 0 and 1 , 145 years for ages 1 and 2 to approximately 1 year for ages 99 and 100 . The expected time until death for last component lives has much surviving time than the expected time until death of the first component lives because in the joint life case, it fails only on the first death of one of the component lives. In this case the probability of death was higher than that of the last survivor where both component lives has to die for the status to fail and by the time the two components might have died the time survived would also have increased. The insurance payable immediately on the death of the first component lives (joint life) was an increasing function of age. Thus, from 0.287 for ages 0 and $1,0.289$ for ages 1 and 2 to 0.952 for ages 99 and 100 . The insurance payable immediately on the death of the last component lives was also an increasing function of age, that is from 0.048 for ages 0 and 1, 0.049 for ages 1 and 2 to 0.894 for ages 98 and 99 . This indicates that a unit insurance payable immediately on the death of first component lives was greater than that of the last survivor. This was because of the variation in the expected time until death of the joint life been much smaller than the last survivor and as such insurance payments on lives with shorter time until death paying more than those with more time until death. The annuity payments until the first death of the component lives was a decreasing function of age, that is from 14.265 for ages 0 and 1, 14.224 for ages 1 and 2 to 0.952 for ages 98 and 99. But age 100 had a higher annuity payment of 20.000 than all the component lives because it was considered to the terminal age. Also the annuity payments until the death of the last component lives was a decreasing function of age, that is from 19.040 for ages 0 and $1,19.025$ for ages 1 and 2 to 2.125 for ages 98 and 99 but ages 99 and 100 had annuity payments of 20.000 since there was an inclusion of the terminal age. In the same way, the annuity payments for the joint life was smaller than the last survivor because the annuity was paid until the first death of one of the component lives and since the expected time until first death was also smaller compared with last survivor. It was also realized that, annuity for the last survivor was continually paid until the last death of the component lives and in this case will make the payments accrual more than that of the joint life. For one to receive a benefit of $\mathrm{GH} \phi 1000$ at $5 \%$ force of interest, the premium to be paid for both the joint life and last survivor was an increasing function of age and that the premium for the joint life was greater than the last survivor since the expected time for the last survivor was greater than the joint life when all other perils are held constant. Again the benefit and force of interest when changed will yield an increasing premium with age when all other perils are held constant.

\section{Conclusion}

This paper compared single life status and multiple life statuses using multiple and single life functions. The analysis revealed that, using age as the main risk evaluation, for single life status and multiple life statuses, their expected time until death are decreasing functions of age. It was realized also that, the premiums for both single life status and multiple life statuses were increasing with age, however the premium for single life was higher than multiple life statuses. In the case of the multiple life statuses, it was revealed that, premium for joint life was greater than the last survivor and that, a change in the interest rate or force of interest and the benefit did not change the trend in premium payments. Also no matter the interest and benefits, an insured for a life policy will have a high premium to pay when the age is high and vice versa and insurers of life products must consider the age of the insured to be able to apply the required premium payments. In considering two lives for life policy coverage, the ages of the two matters in that the age of either life can easily influence the premium payment especially in the case of joint life status in which the premium payments are higher than the last survivor status. Therefore, in pricing these insurances, the age of one is essential in determining the premium.

\section{References}

[1] Black K. Jr., and Skipper H. D. Jr., (1994). Life Insurance. Prentice-Hall, Inc.

[2] Carriere, J. F., \& Chan, (1986). The bounds of bivariate distributions that limit the value of last-survivor annuities. Transactions of the Society of Actuaries, 38: 51-74.

[3] Carriere, J. F., (2000). Bivariate survival models for coupled lives. Scandinavian Actuarial Journal, 5: 17-31.

[4] Denuit, M., and Cornet, A. (1999). Multiple Premium Calculation with Dependent Future Lifetimes. Journal of Actuarial Practice Vol. 7.

[5] Denuit, M., and Teghem, S. (1998). "Measuring the Impact of a Dependence Among Insured Lifelengths". Bulletin de 1' Association Royale des Actuaries Belge: to appear.

[6] Denuit, M., Dhaene, J., Le Bailly de Tilleghem, C. \& Teghem, S. (2001). Measuring the impact of dependence among insured life lengths. Belgian Actuarial Bulletin 3(1): 18-39. 
[7] Dhaene, J., Vanneste, M. and Wolthuis, H. (2000). A note on dependencies in multiple life statuses. Mitteilungen der Schweizerisher Aktuarvereinigung, 4: 19-33.

[8] Frees, E.; Carriere, J.; and Valdez, E., (1996). Annuity Valuation with Dependent Mortality. Journal of Risk and Insurance. 63: 229-261.

[9] Heekyung Y., Arkady S., and Edwin H., (2002). A Reexamination of the Joint Mortality Functions. North American Actuarial Journal. 6(1): 166-170.

[10] Hurliman W., (2009). Actuarial analysis of the multiple life endowment insurance contract. Conference paper (January, 2009), available from Werner Hurliman, retrieved on 19 April 2016.

[11] Jagger C., and Sutton C. J., (1991). "Death After Marital Bereavement-Is the Risk Increased? Statistics in Medicine 10: 395-404.
[12] Norberg, R. (1989). Actuarial analysis of dependent lives. Mitteilungen derSchweiz. Vereinigung der Versicherungsmathematiker, 2: 243-255.

[13] Oakes, D. (1989). Bivariate survival models induced by frailties. J. Americ. Statist. Assoc. 84 (406): 487-493.

[14] Parkes C. M., Benjamin B., and Fitzgerald R. G., (1969). "Broken Heart": A statistical Study of Increased Mortality among Widows. British Medical Journal 1: 740-743.

[15] Yang J., and Zhou S., (1991). "Joint-life status and Gompertz's Law". Mathematical Population Studies 5: 127138.

[16] Youn, H., Shemyakin, A. \& Herman, E. (2002). A reexamination of the joint life mortality functions. North American Actuarial Journal. 6: 166-170. 